\title{
Diagnóstico molecular de SARS-CoV-2
}

\author{
Molecular diagnosis of SARS-CoV-2
}

Gladys Pinilla B. ${ }^{1}$, Claudia Andrea Cruz B. ${ }^{2}$, Jeannette Navarrete O. ${ }^{3}$

\section{Resumen}

El diagnóstico de COVID-19 se basa tanto en aspectos clínicos como en pruebas de detección, pero los síntomas y signos clínicos de los pacientes infectados son altamente atípicos y, por lo tanto, las pruebas moleculares son indispensables para su diagnóstico. La reacción en cadena de la polimerasa con transcriptasa inversa (RT-qPCR) se lleva a cabo en laboratorios nivel BSL II; asimismo, los principales blancos moleculares para la detección viral son el gen E (envoltura), y el gen RdRP (ARN polimerasa dependiente de ARN). Los falsos negativos en este diagnóstico se deben a la calidad y cantidad de la muestra, condiciones de transporte, almacenamiento, y manejo de estas antes y después de la extracción (el ARN es termolábil y abundantes las RNasas), fase de la infección, mutaciones del virus y presencia de inhibidores de la PCR. En estos casos, se recomienda una nueva toma de muestra, especialmente de vías respiratorias bajas, para aumentar la carga viral. Se debe tener en cuenta la sensibilidad analítica de la RT-qPCR (5,2 copias de ARN/reacción) y que, una vez el RNA se extrae, se va degradando progresivamente afectando la sensibilidad diagnóstica de la prueba. Un diagnóstico oportuno permite optimizar el manejo (aislamiento y tratamiento) y monitorización de los pacientes, así como la aplicación de medidas de prevención y control de la expansión, y la vigilancia epidemiológica de la enfermedad.

Palabras claves: diagnóstico, RT qPCR, virus SARS, coronavirus.

\footnotetext{
1. Facultad de Ciencias de la Salud, programa de Bacteriología y Laboratorio Clínico, Universidad Colegio Mayor de Cundinamarca. ORCID: https://orcid.org/0000-0002-3548-344X

2. Facultad de Ciencias de la Salud, programa de Bacteriología y Laboratorio Clínico, Universidad Colegio Mayor de Cundinamarca ORCID: https://orcid.org/0000-0003-1041-9609

3. Facultad de Ciencias de la Salud, Programa de Bacteriología y Laboratorio Clínico, Universidad Colegio Mayor de Cundinamarca. ORCID: https://orcid.org/0000-0003-1935-7125

Correo electrónico de correspondencia: gpinillab@unicolmayor.edu.co
}

https://doi.org/10.22490/24629448.4184 


\section{Abstract}

COVID-19 diagnosis is based on both clinical aspects and screening tests. However, clinical symptoms and signs in infected patients are highly atypical; hence, molecular tests are essential for diagnosis. RT-qPCR is carried out at BSL II level laboratories; the main molecular targets for viral detection are E gene (envelope), and RdRP gene (RNAdependent RNA polymerase). False negatives in this diagnosis are due to sample quality and quantity, transport conditions, storage and handling before and after extraction (RNA is heat-labile and RNases are abundant); infection phase; virus mutations and presence of CRP inhibitors. Taking into account analytical sensitivity of RT-qPCR (5.2 copies of RNA / reaction) and the fact that once RNA it is extracted, it progressively degrades and affects test diagnostic sensitivity, a new sample -specifically taken from the lower respiratory tract in order to increase viral load-is recommended in the abovementioned cases. Timely diagnosis allows optimizing management (isolation and treatment), patient monitoring, implementing prevention and control measures as well as epidemiological surveillance of the disease.

Keywords: diagnosis, RT qPCR, SARS virus, coronavirus.

\section{Introducción}

El síndrome respiratorio agudo severo causado por el coronavirus tipo 2 SARS CoV-2, cuyo mecanismo de patogénesis es poco conocido pero similar a los virus SARS-CoV y MERS, brinda información sobre la genética y el diseño diagnóstico para COVID19 (1). Se han Identificado cuatro géneros de coronavirus: $a, \beta, \gamma, \delta$. Al género $\beta$ pertenecen los ya mencionados; tienen genoma de ARN monocatenario de sentido positivo, tamaño de $26-32 \mathrm{~Kb}$ y longitud de 100 $\mathrm{nm}(2)$.

Las espículas que los caracterizan están compuestas por una glucoproteína (maleable, alta tasa de mutaciones y recombinación) que les ayuda en su adaptación evolutiva y conversión a un patobionte en el ser humano (3). La similitud de genomas con $\mathrm{CoV}$ y MERS evidencia que el origen del virus SARS CoV-2 es natural y surgió por la alta tasa de mutaciones que presentan. Los típicos $\mathrm{CoV}$ contienen al menos diez marcos abiertos de lectura (ORF). Los primeros se traducen en dos poliproteínas grandes y los otros ORF de SARS-CoV-2 codifican para cuatro proteínas estructurales principales: proteínas de espícula (S), envoltura (E), nucleocápside $(\mathrm{N})$ y membrana $(\mathrm{M})$, así como varias proteínas accesorias como orf 3,6 , $7 \mathrm{a}, 7 \mathrm{~b}, 8$ y 9b, que codifican proteínas capaces de evadir la respuesta inmune (4). 
Cuando el virus introduce su ARN a las células, crea millones de copias iguales. Cada virus puede generar entre 10000 y 100000 copias; de esta manera, cada gota respiratoria producida por una persona con infección activa puede tener hasta 100 millones de viriones, que permiten una fácil diseminación viral $y$, por lo tanto, alto contagio (2).

El diagnóstico de COVID-19 se basa en la historia epidemiológica, las manifestaciones clínicas y pruebas de laboratorio como la RT-qPCR, tomografía computarizada, identificación de IgM /IgG por Elisa (5). Sin embargo, los síntomas y signos clínicos de los pacientes infectados son altamente atípicos y, por lo tanto, las pruebas moleculares son indispensables para el diagnóstico. Este se lleva a cabo en laboratorios nivel BSL II, con cámaras de flujo laminar tipo II y filtros EPA. Asimismo, las muestras deben estar en triple envase en contenedores homologados bajo normativa de "Sustancia biológica clase B (UN3373)" y se transpor$\tan$ a $4{ }^{\circ} \mathrm{C}(6)$; las áreas de trabajo que aseguran el correcto manejo de las muestras, está el área sucia para recepción, registro, desembalaje e inactivación de las muestras y el área limpia, para la extracción del ARN y realización de RT-qPCR (7).

La toma y el tipo de muestra dependen de la procedencia y especificaciones clínicas del paciente. Para el ambulatorio se recomienda el hisopado nasofaríngeo y orofaríngeo, recolectados en un mismo tubo con medio de transporte viral, que incrementa la carga viral (108-109copias/hisopado). Si son pacientes hospitalizados, lo adecuado son los aspirados endotraqueal y nasofaríngeo, además el lavado nasal o broncoalveolar, aunque diluye la muestra. El esputo tomado de vías respiratorias bajas contiene más carga viral $(108-1011 / \mathrm{ml})$ y más virus vivos, por lo cual se recomienda después de las 2 semanas de sintomatología (8). Los blancos moleculares de detección más usados para el ensayo de tamizaje de primera línea, está el gen E(envoltura), usado para el diseño de primers y sonda Taqman; si da positivo, se continua con las pruebas confirmatorias usando el gen RdRP (RNA polimerasa dependiente de RNA). Otro blanco usado es el gen Orf1ab (tabla 1) (9). 
Tabla 1. Análisis de resultados de las pruebas moleculares RT-qPCR sonda Taqman.

\begin{tabular}{|c|c|c|c|c|}
\hline $\begin{array}{c}\text { GENES E } \\
\text { Screen de primera línea }\end{array}$ & $\begin{array}{c}\text { CONTROL ENDOGENO } \\
\text { (RNAsa P) }\end{array}$ & $\begin{array}{c}\text { Gen RdRP } \\
\text { Confirmatorio }\end{array}$ & INTERPRETACIÓN & $\begin{array}{l}\text { OBSERVACIONES } \\
\text { FALSOS NEGATIVOS }\end{array}$ \\
\hline Positivo & Positivo & Positivo & $\begin{array}{l}\text { SARS Cov-2 detectado y } \\
\text { confirmado }\end{array}$ & $\begin{array}{l}\text { Umbral de detección } \\
\text { adecuado }\end{array}$ \\
\hline Positivo & Negativo & Positivo & $\begin{array}{l}\text { SARS Cov-2 detectado y } \\
\text { confirmado }\end{array}$ & Alta carga viral \\
\hline Negativo & Positivo & N/A & No detectado & $\begin{array}{c}\text { Buena calidad de muestra, } \\
\text { pero poca carga viral }\end{array}$ \\
\hline Negativo & Negativo & N/A & Resultado inválido & $\begin{array}{c}\text { Calidad de muestra } \\
\text { deficiente e inhibidores de } \\
\text { PCR }\end{array}$ \\
\hline
\end{tabular}

Nota: los genes blanco molecular, deben ser detectados para considerar la positividad viral, mientras que el control endógeno respalda la interpretación, ya que confirma la adecuada toma de muestra, integridad del ARN obtenido y ausencia de inhibidores de la PCR.

Para el diagnóstico de confirmación en zonas sin circulación del virus se necesita la positividad frente a dos genes distintos de COVID-19, uno de ellos específico, o positivo frente a un betacoronavirus, más una identificación al menos parcial del genoma del virus COVID-19. En zonas de transmisión comunitaria, se considera suficiente la positividad de la RT-qPCR para un único gen que sea discriminatorio de COVID-19.

La especificidad de las sondas Taqman permite seguir el rastro de varias reacciones de amplificación independientes en un mismo tubo. Cada sonda se puede diseñar con un fluoróforo que emita a una longitud de onda distinta y el equipo debe tener dife- rentes filtros para cada uno de estos fluoróforos: FAM (emisión a $520 \mathrm{~nm}$ ) y ROX $(623 \mathrm{~nm})$.

Los protocolos más usados son el de París, Centers for Disease Control (CDC) y el de Berlín, recomendado por la Organización Mundial de la Salud (OMS), los cuales se basan en extracción de ARN mediante columnas de afinidad o usando perlas magnéticas; retrotranscripción en un solo paso, es decir junto con la mezcla maestra de qPCR Taqman simple con una sonda, un amplicón por tubo, o múltiple, con dos o más sondas, y varios amplicones por tubo. El análisis de datos se hace determinando el ciclo umbral de detección o Ct de muestras 
por comparación con controles positivos, negativos y endógenos (figura 1). El tiempo total del análisis desde la llegada al laboratorio de las muestras hasta el reporte es de 12 horas, si es método manual para 94 muestras, y 8 horas aproximadamente, si es automatizado $(11,12)$.

Figura 1. Amplificación por RT qPCR de los genes E (SARS-CoV-2) y RNAsa P (control endógeno). En azul se observa el gen $\mathrm{E}$ y en rosado RNAsa.

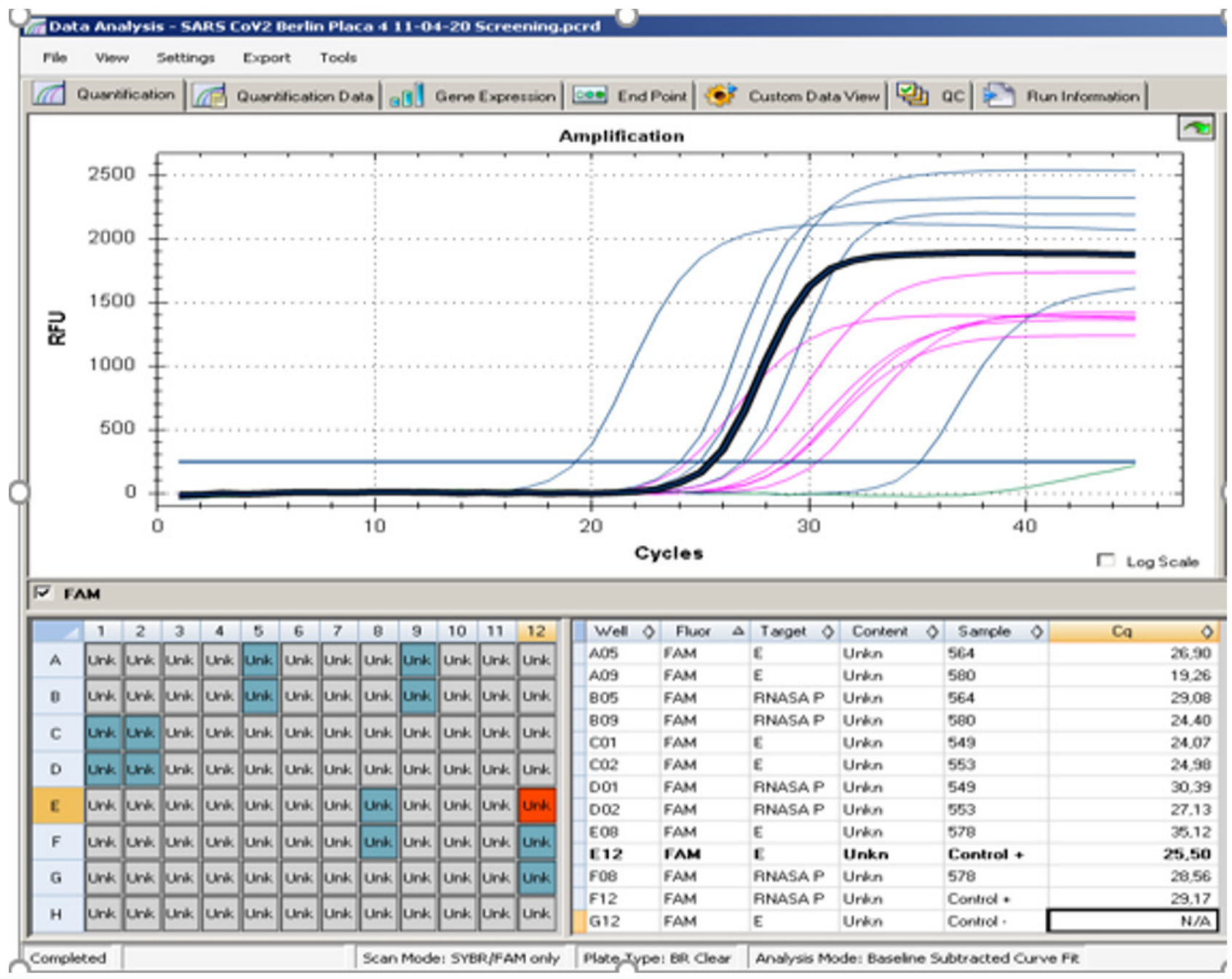

Fuente: Autores.

En cuanto a los falsos negativos, estos son debidos a la calidad y cantidad de la muestra, debido al manejo o envío inadecuados (sin refrigeración). El virus es termolábil y se degrada con facilidad; de hecho, una vez el RNA se extrae, se degrada progresivamente y afecta la sensibilidad. Muestras recogidas durante el pico, muy temprano o fase tardía de la infección; mutaciones del virus, y presencia de inhibidores de la PCR. En estos casos se recomienda una nueva toma de muestra, especialmente de vías respiratorias 
bajas, para aumentar la carga viral, teniendo en cuenta que la sensibilidad analítica de la $\mathrm{RTqPCR}$ es 5,2 copias de ARN/reacción y que estos factores podrían disminuirla.

En cuanto a la especificidad ( $95 \%$ a 100 $\%)$, esta depende de las secuencias de los primers, los cuales se deberían diseñar de acuerdo con la secuenciación de los aislamientos según distribución geográfica (13). La PCR es muy sensible durante las dos primeras semanas de la infección, pero a partir de la tercera semana se va negativizando; por eso, en este punto, se recomienda el apoyo con pruebas rápidas y la detección de anticuerpos. Asimismo, personas positivas deben tener seguimiento y tomarse dos muestras en intervalo de 14 días, las cuales deben ser negativas, para que se consideren no portadoras del virus.

Finalmente, para garantizar resultados confiables se requiere validar y controlar la calidad de pruebas in house" y kits comerciales. Estas pruebas diagnósticas, consideradas en la actualidad como de referencia y de elección para COVID-19, deben seguir las recomendaciones de la FDA $(14,15)$.

\section{Referencias}

1. Corman VM, Eckerle I, Bleicker T, Zaki A, Landt $\mathrm{O}$, Eschbach-Bludau M, et al. Detection of a novel human coronavirus by real-time reverse-transcription polymerase chain reaction. Euro Surveill. 2012;17(39):20285 doi: https://doi.org/10.2807/ ese.17.39.20285-en
2. Drosten C, Gunther S, Preiser W, van der Werf S, Brodt HR, Becker S, et al. Identification of a novel coronavirus in patients with severe acute respiratory syndrome. N Engl J Med. 2003;348(20):1967-76. doi: https://doi.org/ 10.1056/NEJMoa030747

3. Drexler JF, Gloza-Rausch F, Glende J, Corman VM, Muth D, Goettsche M, et al. Genomic characterization of severe acute respiratory syndrome-related coronavirus in European bats and classification of coronaviruses based on partial RNA-dependent RNA polymerase gene sequences. J Virol. 2010;84(21):11336-49. doi: https://doi.org/ 10.1128/JVI.00650-10

4. Wang W, Xu Y, Gao R, Lu R, Han K, et al. Detection of SARS-CoV-2 in Different Types of Clinical Specimens. JAMA. 2020;323(18):1843-4. doi: https://doi.org/10.1001/jama.2020.3786

5. Sociedad Española de Enfermedades Infecciosas y Microbiología Clínica. Recomendaciones institucionales. Documento de posicionamiento de la SEIMC sobre el diagnóstico microbiólogo de Covid-19. [Consultado el 26 de marzo de 2020]. Disponible en https://seimc.org/contenidos/documentoscientificos/recomendaciones/seimc-rc-2020-Posicionamiento_SEIMC_diagnostico_microbiologico_COVID19.pdf

6. Organización Mundial de la Salud. Laboratory testing for 2019 novel coronavirus (2019-nCoV) in suspected human cases. Interim guidance. 19 March 2020. [Consultado el 31 de marzo de 2020]. Disponible en: https://www.who.int/publications/i/ item/10665-331501

7. Centers for Disease Control and Prevention. Interim Guidelines for Collecting, Handling, and Testing Clinical Specimens from Persons for Coronavirus Disease2019 (COVID-19). [Consultado el 28 de marzo de 2020]. Disponible en: https://www.cdc. gov/coronavirus/2019-nCoV/lab/guidelines-clinical-specimens.html

8. Wang W, Xu Y, Gao R, Lu R, Han K, et al. Detection of SARS-CoV-2 in Different Types of Clinical 
Specimens. JAMA. 2020;323(18):1843-44. doi: https://doi.org/10.1001/jama.2020.3786

9. Argoty LA. Instituto Nacional de Salud Micrositio [Consultado el 19 marzo de 2020] Disponible en: http://www.ins.gov.co/Noticias/Paginas/Coronavirus.aspx

10. Loeffelholz MJ, Tang YW. Laboratory diagnosis of emerging human coronavirus infections - The state of the art. Emerg Microbes Infect. 2020;9(1):747756. doi: https://doi.org/10.1080/22221751.2020. 1745095

11. SEIMC. Reflexiones de SEIMC sobre el uso de la detección de antígenos y anticuerpos para diagnóstico de COVID-19. 30 de marzo de 2020. Disponible en: https://seimc.org/contenidos/noticias/2020/ seimc-nt-2020 Reflexiones_deteccion_Ag_y_AC_ COVID-19.pdf. Consultado 9 abril 2020

12. Lineamientos para el uso de pruebas en el laboratorio de salud pública (LSP) en el marco de la emergencia sanitaria por (Covid-19) en Colombia. Ministerio de Salud y Protección Social Bogotá, abril de 2020. [Consultado el 24 de junio de 2020]. Disponible en: https://www.minsalud.gov.co/RID/ lineamientos-pruebas-lsp-covid-19.pdf

13. Corman V M, Landt, O, Kaiser M, et al. Detection of 2019 novel coronavirus (2019-nCoV) by real-time RT-PCR. Euro Surveillance : Bulletin Europeen Sur Les Maladies Transmissibles = European Communicable Disease Bulletin. 2020; 25(3), 1-8. https://doi.org/10.2807/1560-7917. ES.2020.25.3.2000045

14. Gomez J, Castellanos J, Rodriguez A, Cardona J, Forero JE, Mattar S, Esparza G. Consenso de grupo Ad-hoc sobre recomendaciones para la evaluación y controles de calidad para el diagnóstico molecular y serológico de la infección humana por SARS CoV-2. Infectio, 2020;24(3):S2

15. CNBC FDA grants 'emergency use' coronavirus test that can deliver results in 45 minutes. 21 Mar 2020. [Consultado el 31 de marzo de 2020]. Disponible en https://www.cnbc. com/2020/03/21/fda-grants-emergencyuse-coronavirus-test-that-can-deliver-results-in-45-minutes. html 